\title{
A CONTRUÇÃO DE VERDADES PARRESIÁSTICAS EM DISCURSOS SOBRE SUICÍDIO E HETERONORMATIVIDADE
}

\author{
Douglas de Oliveira Domingos ${ }^{1}$ \\ Regina Baracuhy ${ }^{2}$
}

\begin{abstract}
RESUMO: Para filósofos e sociólogos, o ato de tirar a própria vida, embora seja aparentemente individual, é cercado por circunstâncias sociais, visto que o suicídio está circunscrito a uma população. Em comparação a grupos heterossexuais e cisgêneros, a propensão ao suicídio na comunidade LGBTI chega a ser cinco vezes maior. Partimos, então, da problemática de que os sujeitos LGBTI sofrem ainda hoje com discursos que objetivam seus corpos e levam alguns deles ao adoecimento mental e a tentativas de suicídio. Com a disseminação do acesso e dos efeitos das mídias digitais, enunciados-acontecimentos sobre suicídio têm emergido e se acumulado no ambiente virtual, o que também garante visibilidade às fatalidades decorrentes da heteronormatividade. Desse modo, pensando com Michel Foucault, pretendemos analisar três vídeos do YouTube relacionados a tentativas de suicídio, investigando os efeitos de verdade gerados pela discursivização parresiástica das tentativas de suicídio de sujeitos LGBTI no ciberespaço. A metodologia utilizada é a abordagem descritivo-interpretativa, de cunho qualitativo. Mobilizamos principalmente os postulados dos Estudos Discursivos Foucaultianos, com ênfase nas noções de sujeito, corpo discursivo, parresía e confissão. Verificamos até que ponto a resistência provoca incisões através de sacrifícios quase letais que ganham ressonância nas redes digitais.
\end{abstract}

PALAVRAS-CHAVE: Análise do Discurso. Corpo. Heteronormatividade. Parresía. Suicídio.

ABSTRACT: For philosophers and sociologists, the act of taking one's own life, although apparently individual, is surrounded by social circumstances, since suicide is confined to a population. Compared to heterosexual and cistern groups, the propensity for suicide in the LGBTI community is five times higher. We start, then, from the problem of those who are subject to LGBTI even today with speeches that objectify their bodies and lead some of them to mental illness and suicide attempts. With the dissemination of access and effects of digital media, statements about suicidal and emerging events and accumulate in the virtual environment, which also ensures visibility to the heteronormativity fatalities. This way, thinking with Michel Foucault, intends to analyze three YouTube videos related to suicide attempts, investigating the effects of the truth generated by the parresiastic discursivization of suicide attempts by LGBTI individuals in cyberspace. The methodology used is a descriptiveinterpretative approach, of qualitative quality. We mainly mobilize the postulates of Foucaultian Discursive Studies, with an emphasis on the actions of individuals, discourse body,

\footnotetext{
1 Professor efetivo na Secretaria de Educação, Ciência e Tecnologia da Paraíba (SEECT-PB). Mestre em Linguística pelo Programa de Pós-Graduação em Linguística (PROLING - UFPB). Integrante do grupo de pesquisa Círculo de Discussões em Análise do Discurso (CIDADI). E-mail: douglasdeoliveira55@gmail.com. ${ }^{2}$ Professora Associado Nível IV da Universidade Federal da Paraíba, onde ministra disciplinas e orienta pesquisas em nível de Graduação no Departamento de Letras Clássicas e Vernáculas (DLCV) e no Programa de PósGraduação em Linguística (PROLING). Líder do grupo de pesquisa CIDADI. E-mail: mrbaracuhy@ hotmail.com.
} 
PERcursos Linguísticos • Vitória (ES) •v. 10 •n. 25 • 2020 • ISSN: 2236-2592 • Dossiê:

Discursos de resistência e corpos (re)existentes •

participation and confession. We verified the extent to which resistance causes incisions through almost lethal sacrifices that gain resonance on digital networks.

KEYWORDS: Speech analysis; Body; Heteronormativity; Parresia; Suicide.

\section{Introdução}

Figura 1: Velório de Victória Jugnet

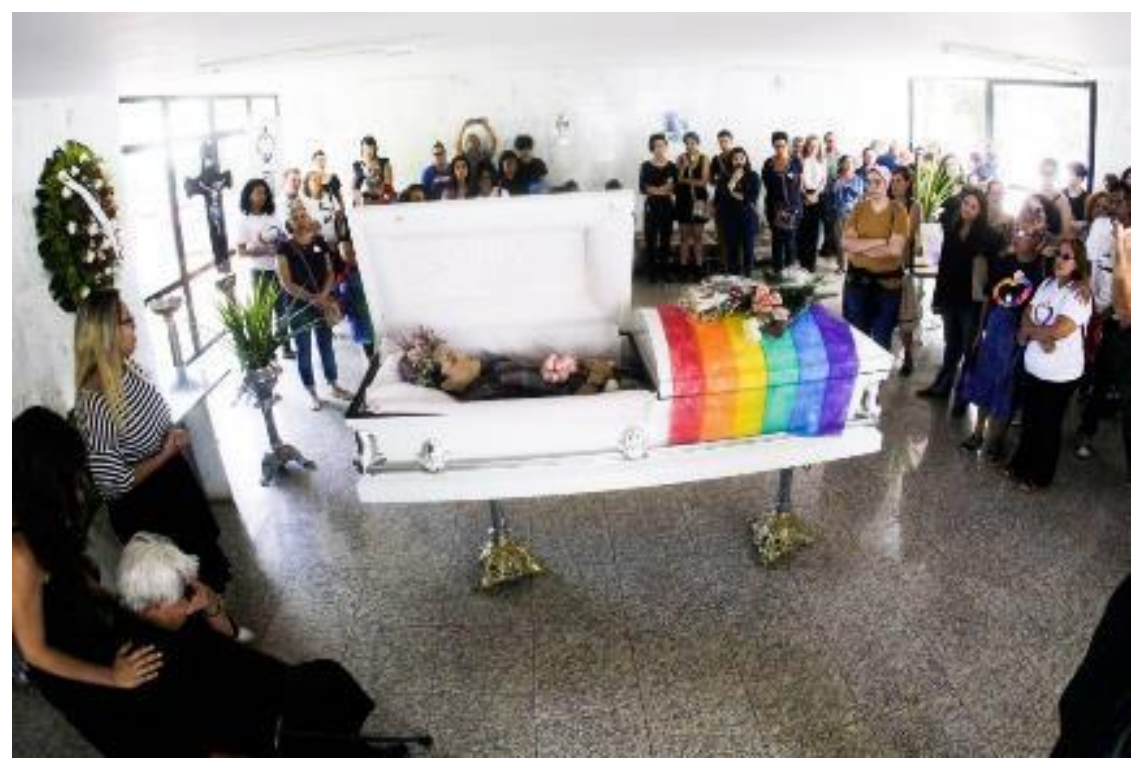

Fonte: https://www.metropoles.com/saude/suicidio-de-garota-trans-brasiliense-provocaapelo-contra-preconceito.

A bandeira colorida que descansa sobre o caixão branco não é mero adorno. A coroa de flores na cabeça da jovem também não; ela nos remete à memória daqueles que triunfaram por alguma razão. Na morte, ambos os objetos põem a brasiliense Victória Jugnet em uma posição diferente daquela que lhe fora imposta ao nascer: lugar de luta e de resistência galgado pela transformação de sua identidade de gênero no país que mais assassina travestis e transexuais no mundo $^{3}$. Entretanto, o patamar de liderança alarmante do Brasil nesse aspecto não contabiliza casos como o de Victória, que ainda sofrem constante interdição pela opinião pública (FOUCAULT, 1999). A jovem de 18 anos não foi vítima de um homicida. Ela tirou a própria vida em janeiro de 2019 após ter publicado, nas redes digitais, um texto no qual reclamava do preconceito e da exclusão que afligem a comunidade LGBTI $^{4}$. Victória é a concretude da estatística, divulgada pela Universidade de Columbia, nos Estados Unidos. Segundo pesquisa

\footnotetext{
${ }^{3}$ Consultar a reportagem "Brasil lidera ranking mundial de assassinatos de transexuais", publicada pelo Correio Braziliense com base nos dados da ONG Transgender Europe (TGEu).

${ }^{4}$ Dentre as diversas siglas possíveis (LGBT, LGBTQ, LGBTQI+), optamos por LGBTI devido à recorrente utilização dessa sigla nos meios de comunicação e na Organização das Nações Unidas (ONU).
} 
PERcursos Linguísticos • Vitória (ES) •v. 10 •n. 25 • 2020 • ISSN: 2236-2592 • Dossiê:

Discursos de resistência e corpos (re)existentes •

publicada em 2012, adolescentes homossexuais, bissexuais e transexuais estão cinco vezes mais propensos a cometer suicídio do que os heterossexuais da mesma faixa etária (SAMORANO, 2017). E é sobre a problematização dessa temática, ao mesmo tempo tão presente e camuflada na sociedade brasileira, que nos debruçamos neste artigo.

A tarefa de falar sobre o inaudível não é tão simples. Embora a sociedade ocidental, no decorrer dos séculos, tenha posto o suicídio em discurso através de documentos institucionais ou de conselhos filosóficos, recriminando-o em grande parte das vezes, esse assunto sofreu intensificadas interdições a partir do século XIX (MINOIS, 2018). Geralmente atrelado à fraqueza de espírito, à possessão diabólica, ao egoísmo ou à loucura, o suicídio desperta incompreensões, estigmas, vergonhas. Na sociedade em que vivemos, cujo principal imperativo é a majoração da vida, falar sobre a morte voluntária escandaliza, choca, constrange, abala os alicerces dos discursos que exaltam a felicidade incessante (BARACUHY; NOGUEIRA, 2018). O vácuo que se abre em decorrência dos discursos propagados no sentido de condenar até mesmo penalmente em algumas épocas - a prática do suicídio se estende aos dias atuais, momento em que assistimos a uma série de rupturas no silêncio secular através do reconhecimento desse problema como questão de saúde pública (SILVA, 2016). A mídia, terreno em que o tabu marcou presença através da ausência de reportagens ou campanhas acerca do tema, começa a se ocupar da prevenção do suicídio, ainda que de maneira dispersa. No Brasil, esse movimento de discursivização encontra uma de suas condições de emergência na campanha Setembro Amarelo, promovida pelo Centro de Valorização da Vida (CVV), pelo Conselho Federal de Medicina (CFM) e pela Associação Brasileira de Psiquiatria (ABP).

Em sentido divergente do que se pressupõe, o suicídio não somente chama a atenção de médicos, psicólogos e outros especialistas da área da Saúde, mas também aguça o pensamento de filósofos, sociólogos - e por que não linguistas? -, que buscam contribuir com a construção de conhecimento em torno desse fenômeno. Embora aparentemente individual, o suicídio está inserido em uma rede de relações sociais que também concorrem para essa escolha fatal. No século XIX, o sociólogo Émile Durkheim propôs a tese de que os processos que possibilitam e confluem com esse tipo de morte não são solitários, mas dependem de uma série de fatores que ligam o sujeito à sociedade.

Nesse sentido, o preconceito - e a crueldade do seu exercício sutil ou desmedido - firmase como um dos problemas sociais mais recorrentes desde que as padronizações civilizatórias convencionaram o comportamento humano, pois "enquanto o sujeito humano é colocado em 
PERcursos Linguísticos • Vitória (ES) •v. 10 •n. 25 • 2020 • ISSN: 2236-2592 • Dossiê:

Discursos de resistência e corpos (re)existentes •

relações de produção e significação, é igualmente colocado em relações de poder muito complexas" (FOUCAULT, 1995, p. 231). No que concerne aos discursos que constituem a heteronormatividade, a aversão à comunidade LGBTI materializa-se em xingamentos, ironias, olhares reprovadores, agressões físicas, homicídios, e - por que não pensar? - suicídios. No Brasil, um levantamento realizado pelo Grupo Gay da Bahia reforça essa ideia. Em 2015, 3\% dos homens homossexuais e $5 \%$ dos bissexuais tentaram cometer suicídio no país contra $0,4 \%$ da população masculina geral brasileira (SAMORANO, 2017).

Diante dessas inquietações, nosso objetivo geral é analisar três vídeos do Youtube relacionados a tentativas de suicídio, entendendo-as como prática de resistência autoinfligida contra os modos de objetivação / subjetivação da heteronormatividade. Especificamente, pretendemos discutir os efeitos de verdade gerados pela discursivização das tentativas de suicídio de sujeitos LGBTI no ciberespaço, atentando para um processo que Foucault chama parresía ou "coragem da verdade".

Nosso corpus é constituído pelos vídeos designados a seguir: vídeo 1 (MINHA TENTATIVA DE SUICÍDIO), publicado pelo canal Mandy Candy em 7 de junho de 2017; vídeo 2 (CURA GAY: TERAPIA OU TORTURA? A VERDADE! - Põe na Roda), publicado em 28 de setembro de 2017 pelo canal Põe na Roda; vídeo 3 (MINHA TENTATIVA DE SUICÍDIO - Qual a sensação de quase morrer?), publicado pelo canal MIMDEXA FALAR no dia 09 de dezembro de 2017.

Como aporte metodológico, mobilizamos os postulados de Michel Foucault sobre sujeito, dispositivo, corpo discursivo, relações de saber-poder e parresía, maciçamente incorporados às pesquisas no campo dos Estudos Discursivos Foucaultianos no Brasil, que se disseminou a partir dos estudos pioneiros da professora Maria do Rosário Gregolin (2006), responsável por trazer as reflexões do filósofo para o campo da linguagem.

\section{Corpo: lugar concreto de poder e resistência}

Ao falarmos sobre o corpo neste artigo, não nos referimos ao conjunto de órgãos que formam, da cabeça aos pés, nem aos sistemas cardiovascular, respiratório, digestório, nervoso, endócrino etc. - a não ser para enxergá-lo como uma fabricação discursiva dos estudos da anatomia biológica, como uma matéria de investimento de saberes que instauram novos modos de percebê-lo e tratá-lo. O corpo a que nos referimos nesta pesquisa é o discursivo, a superfície 
PERcursos Linguísticos • Vitória (ES) •v. 10 •n. 25 • 2020 • ISSN: 2236-2592 • Dossiê:

Discursos de resistência e corpos (re)existentes •

de inscrição dos poderes, o espaço mais concreto - tanto íntimo quanto visível - da nossa existência. Como o poder, essa entidade aparentemente tão abstrata, conseguiria atingir-nos se não fôssemos, nós mesmos, palpáveis? Não podemos nos livrar do nosso corpo, ainda que viajemos "até o fim do mundo ou, de manhã, sob as cobertas", encolhamo-nos, façamo-nos "tão pequenos quanto possível", deixemo-nos "derreter na praia, sob o sol”. Ele estará sempre conosco onde estivermos. Como afirma Foucault, "meu corpo é o contrário de uma utopia, é o que jamais se encontra sob outro céu, lugar absoluto, pequeno fragmento de espaço com o qual, no sentido estrito, faço corpo" (FOUCAULT, 2013, p. 7).

Por essa razão, não devemos pensar "que o corpo tem apenas as leis de sua fisiologia, e que ele escapa à história", mas sim que "ele é formado por uma série de regimes que o constroem; ele é destroçado por ritmos de trabalho, repouso e festa; ele é intoxicado por venenos - alimentos ou valores, hábitos alimentares e leis morais simultaneamente; ele cria resistências" (FOUCAULT, 2017, p. 72). Munidos dessas reflexões, enxerguemos o corpo também enquanto enunciado e instrumento de comunicação. Conforme assevera Milanez (2009, p. 215), pode-se considerar o corpo "não somente como uma simples prática corporal e objetivante, mas também como prática discursiva de resistência". Nesse espaço de encontro, "os discursos são imbricados em práticas não verbais", "o verbo não pode mais ser dissociado do corpo e do gesto", "a expressão através da linguagem se conjuga com a expressão do rosto, de forma a não ser mais possível separar linguagem e imagem" (COURTINE, 2013, p. 31).

Devemos, pois, pensar o corpo como um espaço concreto de construção das identidades, como a materialidade sobre a qual funcionam estratégias de estigmatização - como a fixação de padrões ditos masculinos e femininos -, através das quais os sujeitos resistem a tais práticas higieneizantes (MILANEZ, 2009). Assim, o corpo "é um dos locais envolvidos no estabelecimento das fronteiras que definem quem nós somos, servindo de fundamento para a identidade" (WOODWARD, 2000, p. 15).

Um dos mecanismos de poder que incidem sobre o corpo é a sanção normalizadora. Ela se baseia em regimes de verdade validados pelos saberes socialmente instituídos, de modo que até mesmo o sistema penal procura nas teorias sociológicas, psicológicas, médicas e psiquiátricas, as justificativas para sua ação, “como se a própria palavra da lei não pudesse mais ser autorizada, em nossa sociedade, senão por um discurso de verdade" (FOUCAULT, 1999, p. 19). Esses saberes convocam divisões dos sujeitos conforme as observações dos comportamentos dos corpos perante parâmetros de normalidade pautados em regimes de 


\title{
Discursos de resistência e corpos (re)existentes •
}

verdade. As práticas divisoras agem sob a perspectiva da objetivação, classificando, separando os indivíduos em "o louco e o são, o doente e o sadio, os criminosos e os "bons meninos"” (FOUCAULT, 1995, p. 231), o normal e o anormal, enfim:

\begin{abstract}
A arte de punir, no regime disciplinar, não visa nem a expiação, nem mesmo exatamente a repressão. Põe em funcionamento cinco operações bem distintas: relacionar os atos, os desempenhos, os comportamentos singulares a um conjunto, que é ao mesmo tempo campo de comparação, espaço de diferenciação e princípio de uma regra a seguir. Diferenciar os indivíduos em relação uns aos outros e em função dessa regra de conjunto - que se deve fazer funcionar como base mínima, como média a respeitar ou como o ótimo de que se deve chegar perto. Medir em termos quantitativos e hierarquizar em termos de valor as capacidades, o nível, a "natureza" dos indivíduos. Fazer funcionar, através dessa medida "valorizadora", a coação de uma conformidade a realizar. Enfim traçar o limite que definirá a diferença em relação a todas as diferenças, a fronteira externa do anormal [...]. A penalidade perpétua que atravessa todos os pontos e controla todos os instantes das instituições disciplinares compara, diferencia, hierarquiza, homogeneiza, exclui. Em uma palavra, ela normaliza (FOUCAULT, 2014, p. 179-180, grifo do autor).
\end{abstract}

Essa normalização recai sobre toda a sociedade no momento mesmo em que caímos nas armadilhas preconceituosas, que rotulam os sujeitos de acordo com os parâmetros de normalidade formulados pelos regimes de verdade dos saberes institucionalizados. Recai também sobre o comportamento viril e másculo que se espera de homens - sejam heterossexuais, sejam homossexuais - em uma ditadura heteronormativa. Recobre de loucura, covardia, coragem, doença os corpos daqueles que nutrem ideações suicidas ou tentaram cometer o irreversível; com essa capa de anormalidade, marginaliza-os e os impelem ao silêncio, ao esquecimento.

Entretanto, esse lugar corporal de sofrimento e submissão destinado aos indivíduos que compõem uma população governada pelos mecanismos disciplinares não está fadado à eternidade. Ao descrever a maquinaria de poder que adestra e dociliza nossos corpos a seu bel prazer, Michel Foucault não considera que os sujeitos sejam meros receptáculos desse controle contínuo, mas essencialmente resistentes, de maneira heterogênea, dispersa. Não há $o$ poder, mas relações de poder, lutas travadas no cotidiano entre sujeitos sociais, resistências às formas de dominação que aprisionam os corpos aos rótulos, às condutas normais, à disciplina homogeneizante. Roberto Machado (2017, p. 18) enfatiza esse caráter provisório e plural das forças que se digladiam na sociedade: “como onde há poder, há resistência, não existe propriamente o lugar de resistência, mas pontos móveis e transitórios que também se distribuem por toda a estrutura social”. 
PERcursos Linguísticos • Vitória (ES) •v. 10 •n. 25 • 2020 • ISSN: 2236-2592 • Dossiê:

Discursos de resistência e corpos (re)existentes •

Segundo Foucault, se as resistências não existissem, a História não avançaria. Também não haveria relações de poder sem as possibilidades de reação a ele. Em uma situação de total escravidão - punhos e pés acorrentados, boca silenciada, corpo enclausurado na masmorra -, o que funciona é a dominação e não o poder (FOUCAULT, 1995). Assim, o filósofo nos convida a refletirmos, não apenas sobre quem somos nós hoje, constituídos por essas relações perenes, mas, principalmente, sobre como podemos ser diferentes do que somos, a partir das oportunidades de resistência surgidas através da compreensão sobre o modo com que os poderes nos adestram.

\section{A construção de verdades pela parresía}

Uma das maneiras de resistir com o próprio corpo é a parresía. Essa prática pode ser "traduzida" em uma expressão: "coragem da verdade". O sujeito parresiasta profere um dizer que se relaciona a sua própria experiência; a força da sua verdade se encontra no próprio corpo, no testemunho de vida. Conforme Foucault (2011, p. 13) nos assevera, a parresía é, portanto, "a coragem da verdade naquele que fala e assume o risco de dizer, a despeito de tudo, toda a verdade que pensa, mas é também a coragem do interlocutor que aceita receber como verdadeira a verdade ferina que ouve". Ao tratar de heteronormatividade e suicídio, temas ainda considerados tabus na sociedade contemporânea, os sujeitos que aparecem em nosso corpus põem-se no fogo cruzado dos xingamentos, da exclusão, dos estigmas; oferecem a própria face aos eventuais tapas reativos à atitude de coragem de expor as experiências dolorosas que denunciam as violências hegemônicas da sociedade.

Em vez de reservarmos uma seção teórica sobre a parresía como processo de constituição de subjetividades e verdades, optamos por realizar uma operação de simultaneidade entre os conceitos filosóficos e a efetiva análise discursiva do corpus. Por isso, é chegado o momento de abordarmos resumidamente as questões tratadas em cada vídeo para que, enfim, prossigamos à análise proposta.

O vídeo 1 (MINHA TENTATIVA DE SUICÍDIO), publicado pelo canal Mandy Candy em 7 de junho de 2017, traz a própria youtuber transexual Amanda Guimarães relatando sua tentativa de suicídio. A principal motivação para a produção do vídeo surgiu quando Amanda recebeu uma carta de uma seguidora que passa por dificuldades no processo de transição de identidade de gênero e tem pensamentos suicidas. Ao se sensibilizar com a situação da remetente, a youtuber narra sua própria experiência com a tentativa de suicídio. Em seu canal, 
PERcursos Linguísticos • Vitória (ES) •v. 10 •n. 25 • 2020 • ISSN: 2236-2592 • Dossiê:

Discursos de resistência e corpos (re)existentes •

cujo número de seguidores se aproxima de dois milhões, Amanda traz temas variados, como opinião sobre produtos cosméticos, diários de seu cotidiano ou comentários sobre o mundo artístico. Também são recorrentes conteúdos sobre sua transição e as dificuldades enfrentadas nesse processo.

O vídeo 2 (CURA GAY: TERAPIA OU TORTURA? A VERDADE! - Põe na Roda), publicado em 28 de setembro de 2017 pelo canal Põe na Roda, mostra os depoimentos de um homem e uma mulher homossexuais, Vinícius e Raiane, sobre as pseudoterapias de "reversão sexual" a que foram submetidos em um contexto religioso. Não há, nem no título nem na descrição do vídeo, referências à tentativa de suicídio. Entretanto, ao assistirmos o conteúdo na íntegra, percebemos que Raiane fala brevemente sobre seu processo de adoecimento mental e sobre sua experiência de tentativa de suicídio, ao passo que Vinícius menciona sua relação com o sofrimento psicológico e reconhece a recorrência de reações extremas como a mencionada pela jovem. Além desse vídeo, o Põe na Roda produz conteúdos que debatem sobre homossexualidade, bissexualidade e transexualidade com bastante humor. Seu número de inscritos ultrapassa a marca de um milhão.

No vídeo 3 (MINHA TENTATIVA DE SUICÍDIO - Qual a sensação de quase morrer?), publicado pelo canal MIMDEXA FALAR no dia 09 de dezembro de 2017, o youtuber Igor Lucas explica detalhadamente suas ideações suicidas, relatando aspectos da infância e da adolescência que o levaram a um processo depressivo. Ele narra, passo a passo, os métodos e os efeitos envolvidos na tentativa de suicídio. Dentre os conteúdos produzidos no canal, estão vídeos cujos temas contemplam a comunidade LBGTI e outros em que o youtuber insere suas vivências cotidianas. O número de seguidores é pequeno em relação aos canais anteriores $\neg$ pouco mais de 50 mil. Contudo, o vídeo selecionado para este artigo possui quase cem mil visualizações e mais de dois mil comentários, o que nos garante um farto material de análise principalmente no último capítulo, que investiga os efeitos da discursivização das tentativas de suicídio de sujeitos homossexuais e transexuais no ciberespaço.

De posse das reflexões teóricas precedentes e dessas informações essenciais sobre o corpus, continuemos nosso percurso rumo à execução das análises discursivas a partir da seguinte indagação: de que maneira Mandy Candy, Raiane, Vinícius e Igor Lucas se servem do discurso e das redes digitais para resistir e se libertar dos traumas ocasionados pelas objetivações que incidem nos seus corpos? Que práticas podemos identificar em seus enunciados como facilitadoras da construção de subjetividades e verdades? 
PERcursos Linguísticos • Vitória (ES) •v. 10 •n. 25 • 2020 • ISSN: 2236-2592 • Dossiê:

Discursos de resistência e corpos (re)existentes •

Respondamos previamente, a fim de sintetizar as informações. Em todos os vídeos, enxergamos o atravessamento constitutivo da escrita audiovisual de si, estratégia comumente utilizada por youtubers para falarem de maneira dinâmica sobre si próprios no que concerne a sentimentos, acontecimentos, rotinas, preferências, qualidades e defeitos pessoais, dentre outros aspectos. Em alguns desses enunciados, a escrita de si é formada por, pelo menos, dois recursos discursivos: a confissão e a parresía. Esses três mecanismos de linguagem revelam que os sujeitos se conhecem melhor quando se ocupam de si mesmos (FOUCAULT, 2006). E, ao cuidarem de si, também cuidam de outras pessoas, a exemplo dos internautas que passam por dificuldades semelhantes e se sentem reconfortados ao assistirem aos vídeos. Esse processo acarreta um governo não mais das instituições sobre o sujeito, mas do sujeito sobre si mesmo. Além disso, a credibilidade proporcionada pela discursivização das próprias verdades leva a um certo domínio sobre os outros, cujos pensamentos e atitudes passam a ser governados também pela legitimação da experiência do youtuber através do seu testemunho de vida.

Primeiramente, identifiquemos a confissão. Esse procedimento, tão caro à Igreja Católica, reconfigura-se no espaço digital. Ao expor suas imagens em rede no YouTube, os sujeitos devem responder a um imperativo fundamental dessa plataforma digital: a revelação de seu cotidiano, de suas intimidades (JENKINS, 2009). Sob essa perspectiva, não há a figura do padre como interlocutor no confessionário. Os usuários do YouTube é que ocupam a função da "instância que requer a confissão". Observe os enunciados a seguir:

Essa não é a primeira, não é a segunda, e eu tenho certeza que não vai ser a última mensagem que eu vou receber assim de pessoas que estão passando pelo mesmo que eu passei. Então, Amanda ou você que talvez não esteja vendo uma saída pra sua dificuldade, pro seu problema, eu vou contar uma coisa que eu nunca contei pra ninguém. Nem minha família sabe. Eu meio que me envergonho de... disso, né? E eu acho importante compartilhar isso pra vocês porque se eu hoje consigo tá aqui gravando um vídeo, ter realizado tantas coisas, tantos sonhos na minha vida, eu tenho certeza que você também vai conseguir (Mandy Candy, vídeo 1).

Desde os 12 anos eu comecei a participar de um grupo de oração. E eu... era... me estranhava a forma como que eu me sentia atraída por mulheres. Então eu sempre começava as minhas amizades e eu me afastava, por medo. Medo do que eu poderia sentir por aquela pessoa. [...] Quando eu fiz 16 anos, eu fiquei com a primeira menina. E aí eu contei pro meu coordenador de grupo de oração. E ele ficou assim... Sabe, tipo... Oi?! (Raiane, vídeo 2)

A minha adolescência foi marcada por choro. Eu chorava dia sim, dia sim na minha cama, todos os dias na hora de dormir. [...] E aí, automaticamente bastava um olhar, passar na rua e ver um cara lindo passando e eu olhava e falava: "Nossa, que gato, e tal...". Pronto, aquilo era o suficiente pra acabar comigo mesmo. E aí eu entrava em desespero, porque aí era onde eu via: “cara, não aconteceu, eu não fui curado” (Vinícius, vídeo 2).

E aí eu acho que eu comecei a colocar nas pessoas que me desejavam, sabe? A minha autoestima tava nelas. Então quando eu não estava com uma pessoa, a minha autoestima chegava ao zero e aí eu me sentia deprimido. Enfim, aí me oferecia cigarro e eu fumava, me ofereciam bebida e eu bebia... Sabe? É uma falta de personalidade muito grande. Na verdade, eu acho que é um desespero pra ser aceito em algum lugar, um desespero pra tentar fazer parte do mundo também, eu acho (Igor Lucas, vídeo 3). 
Além do conteúdo sensível presente nos enunciados acima, podemos perceber uma regularidade nos trechos destacados: os sujeitos expressam não apenas os acontecimentos pessoais, mas também os sentimentos que estavam envolvidos neles. Vergonha, medo, desespero, baixa autoestima. O relato de tais emoções nos aproxima da humanidade desses indivíduos e confere às suas palavras efeitos de verdade inerentes ao gesto de desnudar seu ser, suas reações afetivas às situações cotidianas. Todos os sujeitos falam sobre acontecimentos difíceis que provavelmente esconderam, por algum tempo, até mesmo dos mais próximos; são confidências que, naquele momento, certamente os fragilizaram.

A esse recurso de erguimento de verdades testemunhais e soerguimento de vidas marginalizadas, alia-se outro: o "dizer verdadeiro", a "coragem da verdade" ou, simplesmente, "parresía". Através dela, os sujeitos chocam-se com o poder e emergem do anonimato (FOUCAULT, 2003). Devemos buscar, simultaneamente, as grades cerradas de poder que tornam possível declararmos que os sujeitos proferem enunciados parresiásticos ou "corajosos". Em sua aula inaugural no Collège de France, Michel Foucault nos apresentou algumas dessas grades e chamou-as de princípios externos de controle dos discursos ou procedimentos de exclusão. Dentre eles, estão a interdição, a segregação da loucura e a vontade de verdade. Vejamos seus conceitos e a que eles dizem respeito em nossa análise.

Interdição. Em todas as esferas da sociedade, há discursos cuja circulação está submetida a regras que a restringem, limitam. À interdição, deve-se este princípio: "não se tem o direito de dizer tudo, não se pode falar de tudo em qualquer circunstância, qualquer um, enfim, não pode falar de qualquer coisa" (FOUCAULT, 1999, p. 9). Para o filósofo, a região da sexualidade é uma das mais afetadas por esse procedimento. Os vídeos aqui analisados evocam discursos comumente censurados em uma sociedade heteronormativa, que se digladiam com esferas polêmicas, como a religiosa. Além disso, os sujeitos relacionam a heteronormatividade ao suicídio, outro assunto tabu em nossa sociedade. Observe os enunciados a seguir:

Todo o respaldo que eles dão são sempre alguns poucos versículos de bíblia que são soltos, isolados. E com isso eles tentam, tipo, mexer com a cabeça das pessoas. Só te tiram a felicidade e o prazer da vida. O prazer de viver. (Vinícius, vídeo 2)

Esse processo de mudança, ele tortura. Sabe? E eu sou a prova viva disso, do quanto que isso me machucou, o quanto que isso me destruiu, assim... A aceitação me curou. Quem acredita em Deus, universo, seja lá o que for... Eu acho que ele não tá... ele não se importa com quem eu tô beijando, com quem eu amo, ele quer saber o meu coração. E o meu coração tá leve, tá feliz, meu coração que retribuir pro mundo tudo aquilo de bom que eu sinto. Eu falo, se eu pudesse ter me aceitado assim antes, teria evitado passar por tanta coisa... Tantos traumas... (Raiane, vídeo 2) 
PERcursos Linguísticos • Vitória (ES) •v. 10 •n. 25 • 2020 • ISSN: 2236-2592 • Dossiê:

Discursos de resistência e corpos (re)existentes •

Por muitas décadas, os meios de comunicação se omitiram em relação ao suicídio devido à ideia de que publicar reportagens sobre mortes voluntárias poderia levar a uma onda de atitudes semelhantes por um processo de "imitação" (DAPIEVE, 2007). Essa noção advém do início do Romantismo na Alemanha, época na qual o livro Os Sofrimentos do Jovem Werther (1774), de Johann Goethe, teve uma repercussão negativa na população. O nível de suicídio entre os jovens no país aumentou nesse período e muitos dos cadáveres foram encontrados segurando um exemplar da história de Werther, um rapaz que tira a própria vida após sofrer desilusões amorosas. Mais de dois séculos depois, a Organização Mundial de Saúde (OMS) publicou um manual para profissionais da mídia enfatizando a necessidade de se falar sobre o tema no sentido da prevenção, e oferecendo orientações acerca das maneiras de se abordá-lo com responsabilidade (OMS, 2000). No Brasil, nos últimos quatro anos, o suicídio tem ganhado notório destaque na mídia, geralmente em um mês específico do ano. A campanha de conscientização Setembro Amarelo, criada pelo Centro de Valorização da Vida (CVV), pelo Conselho Federal de Medicina (CFM) e pela Associação Brasileira de Psiquiatria (ABP) tem promovido esse debate. Essa breve arqueologia nos atesta que estamos diante de um assunto tabu cujas singularidades são vagarosamente desconstruídas na sociedade. Os sujeitos dos vídeos, então, desafiam as interdições que recobrem o suicídio usando plataformas mais democráticas para fazer reverberar sua mensagem (LEMOS, 2010). Apesar disso, ainda encontramos rastros das proibições no vídeo de Igor Lucas, por exemplo, como se pode observar na figura abaixo:

Figura 2: Tela que antecede a reprodução do vídeo.

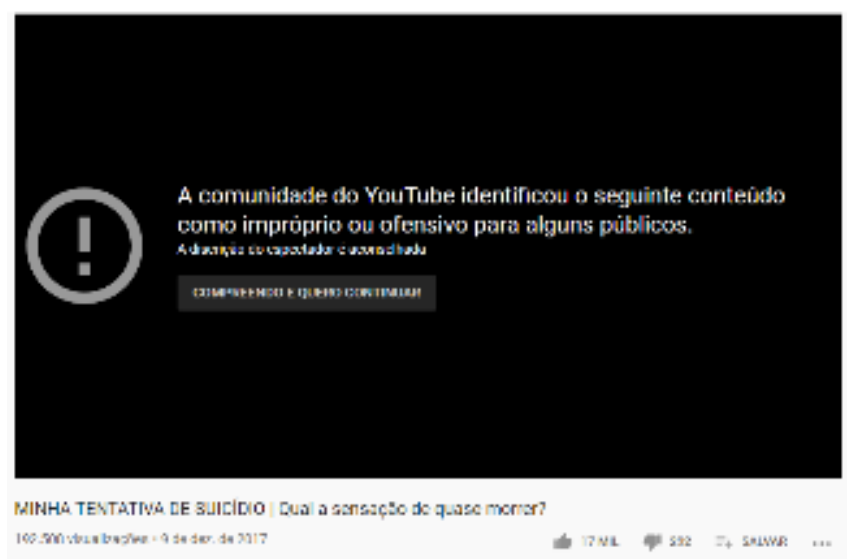

Fonte: Print feito pelo autor.

Ao desafiar as interdições com a parresía, os sujeitos assumem os riscos de serem excluídos, mal vistos, julgados e contestados por pessoas fundamentalistas. Esse é um atributo 
PERcursos Linguísticos • Vitória (ES) •v. 10 •n. 25 • 2020 • ISSN: 2236-2592 • Dossiê:

Discursos de resistência e corpos (re)existentes •

inerente ao "dizer verdadeiro", segundo Foucault (2011, p. 12): “o sujeito, [ao dizer] essa verdade que marca sua opinião, seu pensamento, sua crença, tem de assumir certo risco [...] Para que haja parresía é preciso que, dizendo a verdade, se abra, se instaure e se enfrente o risco de ferir o outro, de irritá-lo, de deixá-lo com raiva". Podemos enxergar algumas dessas respostas nos comentários dos internautas. Elas, porém, são raras, pois o consumo de vídeos no YouTube acontece de acordo com as preferências e identificações dos usuários, o que acarreta uma enxurrada de comentários apoiadores (JENKINS, 2009).

Figura 3: Comentários de repúdio ao conteúdo dos vídeos.

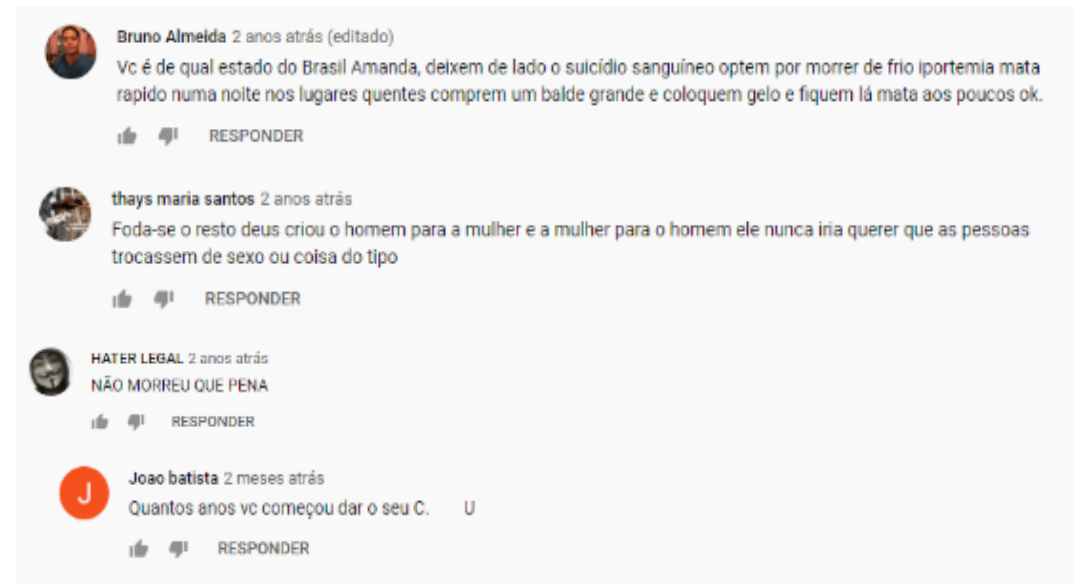

Fonte: print feito pelo autor.

Marcados por ironias e termos pejorativos, os comentários acima materializam os riscos advindos da "coragem da verdade". Superexpostos em rede, os indivíduos se submetem também a discursos que reforçam as objetivações das quais tentam se livrar. Embora as palavras aí contidas possam afetar minimamente os sujeitos dos vídeos, as ações de pessoas próximas que assistiram aos conteúdos e discordam de maneira atroz representam, de maneira incisiva, os riscos dos quais falava Foucault.

Segregação da loucura. Esse procedimento se refere ao binômio "razão/loucura", que baliza aqueles que são considerados "loucos" de "desrazão". Dessa forma, há uma descrença quanto ao seu dizer na sociedade, geralmente rebaixado ao descrédito. "Pode ocorrer que sua palavra seja considerada nula e não seja acolhida, não tendo verdade nem importância, não podendo testemunhar na justiça, não podendo autenticar um ato ou um contrato [...]" (FOUCAULT, 1999, p. 11). O suicídio é majoritariamente discutido a partir da saúde mental, campo que ainda sofre com recorrentes preconceitos perante outras áreas da Medicina (SILVA, 2016). Os propensos suicidas, em geral, são denominados por estigmas que descredibilizam sua 
PERcursos Linguísticos • Vitória (ES) •v. 10 •n. 25 • 2020 • ISSN: 2236-2592 • Dossiê:

Discursos de resistência e corpos (re)existentes •

fala e o marginalizam. Conforme apontam Milanez e Prata (2016, p. 10), esses estereótipos "pretendem eximir a sociedade das obrigações referentes ao sujeito suicida, atribuindo a ele total responsabilidade de sua morte. Fraqueza psicológica, espiritual, distúrbios depressivos, enfim, a lista é vasta quando se pretende responsabilizar o sujeito suicida pelo seu ato". Nos enunciados abaixo, percebemos que o sentimento de vergonha, consequente desses discursos de preconceito, aloja-se também em Mandy Candy. Já Igor Lucas inicia o vídeo destacando a necessidade de desconstrução de tais estigmas.

$\mathrm{E}$, morrendo de vergonha, não contei isso [tentativa de suicídio] pra ninguém, tô contando agora pra vocês, tô contando pra todo mundo, minha família deve tá sabendo agora... (Mandy Candy, vídeo 1)

Eu não quero que vocês levem esse vídeo pro lado da vitimização. Eu não quero não, sério! Não levem esse vídeo pro lado da vitimização ou sei lá... "Que dó!”, “O coitado”, “Ah, meu Deus”... Não, gente, é só uma conversa, sabe? Eu acho que essa vitimização em cima... Isso vem do tabu que tem em cima desse tipo de assunto. (Igor Lucas, vídeo 3)

Dessa forma, além de exercer a coragem de serem vistos como "loucos" ou "fracos na fé”, os sujeitos dos vídeos praticam a parresía, ao evidenciarem suas tentativas de suicídio, não apenas como resultado de uma individualidade, mas também de uma coletividade doente que exclui os desviantes da norma heterossexual. Portanto, podem ser duplamente segregados: pelo estigma em torno dos transtornos mentais e pelo preconceito sobre sua orientação sexual ou identidade de gênero.

Vontade de verdade. Esse procedimento parte da noção foucaultiana de que cada época tem suas proposições verdadeiras, construídas pelos discursos cuja ordem encontra, na incessante repetição pela sociedade e instituições, sua vigência e legitimidade. A vontade de verdade apoia-se sobre um suporte institucional: "é ao mesmo tempo reforçada e reconduzida por todo um compacto conjunto de práticas [...], pelo modo como o saber é aplicado em uma sociedade, como é valorizado, distribuído, repartido e de certo modo atribuído" (FOUCAULT, 1999, p. 17). Desse modo, diversas vontades de verdade constituíram o suicídio no decorrer dos séculos: ele foi, por vezes, silenciado devido à repressão dos poderes absolutistas e dos dirigentes religiosos, à conotação negativa da "loucura" frente aos diagnósticos psiquiátricos e aos manicômios, ao discurso de felicidade que exalta a vida e rechaça a morte; também foi amplamente discursivizado em decorrência das reformas na psiquiatria, das campanhas de conscientização, e de produtos midiáticos como a série norte-americana 13 Reasons Why ou o perigoso jogo Baleia Azul - cujos ápices de debate, no Brasil, aconteceram em 2017. Conforme mencionamos na introdução deste trabalho, todos os vídeos encontrados no YouTube, em que 
PERcursos Linguísticos • Vitória (ES) •v. 10 •n. 25 • 2020 • ISSN: 2236-2592 • Dossiê:

Discursos de resistência e corpos (re)existentes •

os indivíduos relatam a própria tentativa de suicídio, foram publicados a partir de 2017. Embora parresiásticos, os enunciados aqui analisados lutam contra verdades reinantes sobre o suicídio em nossa sociedade, ancorando-se em vontades de verdade que fomentam o debate sobre o tema, a exemplo daquelas produzidas por 13 Reasons Why e pelo Setembro Amarelo. Perceba que, no trecho abaixo, Igor Lucas mobiliza saberes estatísticos para validar ainda mais seu testemunho e enquadrá-lo em uma vontade de verdade que ganha espaço na contemporaneidade:

Uma porcentagem enorme da população mundial vive com depressão, com ansiedade, e é claro que uma grande parte dela não sabe. Porém, a depressão ela é uma coisa que tá muito evidente, sabe, hoje em dia? E o suicídio tá cada vez mais aparecendo nas estatísticas de morte. Inclusive o suicídio é responsável por $2 \%$ das mortes mundiais. Então isso é muita coisa, cara! Pode parecer pouco, mas assim... 800 mil pessoas morrem anualmente por causa do suicídio. Então não é uma coisa que deve ser tratada dessa forma, sabe? É só mais um problema, é só uma doença que precisa ser discutida, que precisa tá em alta. Assim como o câncer é combatido, sabe, a depressão e a ansiedade, o suicídio também precisa ser combatido! (Igor Lucas, vídeo 3).

Além de acoplar discursos institucionais ao seu enunciado, Igor Lucas, assim como os outros sujeitos, usa o testemunho de suas próprias experiências para produzir a relação entre si mesmo e verdade. Para Foucault (2011, p. 11), a parresía "consiste em dizer a verdade, sem dissimulação nem reserva nem cláusula de estilo nem ornamento retórico que possa cifrá-la ou mascará-la [...] O parresiasta dá sua opinião, diz o que pensa, [...] liga-se a essa verdade, e se obriga, por conseguinte, a ela e por ela". O filósofo ainda acrescenta a necessidade do estatuto do outro, que reconhece e legitima o enunciado parresiástico. No YouTube, a maioria dos comentários apresentam sentimentos de identificação e retribuição positiva. Eles, portanto, não questionam a veracidade do conteúdo publicado - não desconfiam, por exemplo, da recuperação dos indivíduos após a ingestão dos medicamentos -, mas partem do pressuposto de que os sujeitos transmitem situações reais; compadecem-se com suas experiências de preconceito e tentativa de suicídio. 
PERcursos Linguísticos • Vitória (ES) •v. 10 •n. 25 • 2020 • ISSN: 2236-2592 • Dossiê:

Discursos de resistência e corpos (re)existentes •

Figura 4: Comentários de apoio ao conteúdo dos vídeos.

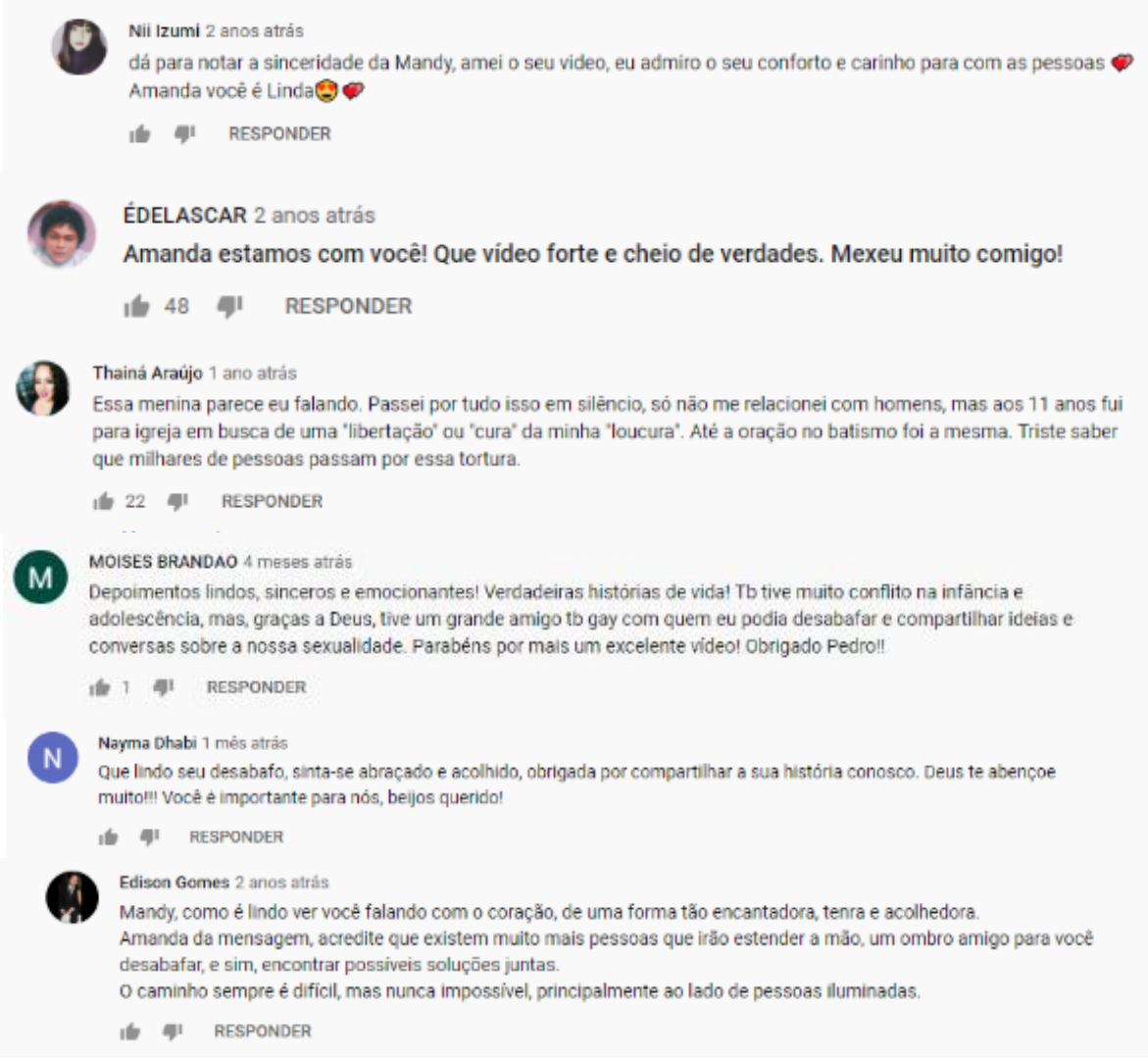

Fonte: print feito pelo autor.

ntos

lindos, sinceros e envolventes", "desabafo" sintetizam a legitimidade concedida pelo estatuto do outro para o fortalecimento das verdades construídas nos depoimentos. A relação entre os vídeos e os comentários analisados nos demonstra "sob que forma, em seu ato de dizer a verdade, o indivíduo se constitui e é constituído pelos outros como sujeito que pronuncia um discurso de verdade" (FOUCAULT, 2011, p. 04).

A partir desses enunciados, percebemos que, cientes dos controles que os feriam e ocupados com a estetização da própria alma, os sujeitos se agarraram à urgência de reviver, de buscar o equilíbrio de suas emoções, de resistir às endemias sociais que contagiavam seu corpo. Trilhando esse caminho pedregoso de lutar em vida e pela vida, entendemos que sobreviver é um ato contínuo e frutífero de resistência.

\section{Considerações finais}

Partindo de enunciados presentes nos vídeos e em alguns dos comentários dos internautas, analisamos a constituição de verdades e subjetividades através das técnicas de si, 
PERcursos Linguísticos • Vitória (ES) •v. 10 •n. 25 • 2020 • ISSN: 2236-2592 • Dossiê:

Discursos de resistência e corpos (re)existentes •

mobilizando os conceitos de confissão e parresía. Tais processos, estudados por Foucault através de textos da Antiguidade, mostraram-se extremamente oportunos e atualizados por uma sociedade digitalizada e midiatizada. Constatamos, assim, que é preciso remontar ao passado para entendermos as práticas discursivas sociais que se concretizam no presente.

Propusemos, neste artigo, uma reflexão sobre as relações sociais de saber-poder que levam ao sofrimento psíquico e à discursivização do suicídio como uma "reação", uma forma "corajosa" de resistir. Reflexão revogável, arremessada ao rio descontínuo da história. Este, afinal, é um dos fundamentos dos Estudos Discursivos Foucaultianos: oferecer alternativas para um processo de leitura crítica da sociedade, escavando saberes que constroem o verdadeiro de cada época e instauram poderes, admitindo a existência de inúmeros gestos de interpretação dos quais jamais extrairemos a verdade absoluta.

Este artigo não é sobre morte, mas sobre vida. Na análise discursiva aqui empreendida, estamos falando não apenas sobre suicídio, mas principalmente sobre a valorização do viver, sobre como podemos agir enquanto sociedade para impedir que os outros seres humanos se desfaçam em ruínas emocionais. Este trabalho nos faz refletir sobre práticas de respeito e de empatia que estão ao nosso alcance. Precisamos, sim, falar sobre suicídio! Mas é necessário, acima disso, falar - e agir - com cuidado, compreensão, acolhimento, amor. Precisamos falar sobre vida. Para toda a humanidade.

\section{Referências}

BARACUHY, R.; NOGUEIRA, K. O discurso da felicidade como tática biopolítica na revista SuperInteressante. Revista Discursividades, Campina Grande, n. 2, mar. 2018.

CANDY, M. MINHA TENTATIVA DE SUICÍDIO. 2017. (08m12s). Disponível em: <https://youtu.be/lzY-xEF2YHI> Acesso em: 27 ago 2019. (Vídeo do Youtube)

COURTINE, J. J. Decifrar o corpo: pensar com Foucault. Petrópolis: Vozes, 2013.

DAPIEVE, A. Morreu na contramão: o suicídio como notícia. Rio de Janeiro: Zahar, 2007.

FOUCAULT, M. A Coragem da verdade: O governo de si e dos outros II: curso no Collège de France (1983-1984). 1. ed. Tradução de Eduardo Brandão. São Paulo: Editora WMF Martins Fontes, 2011.

FOUCAULT, M. A hermenêutica do sujeito. Tradução de Márcio Alves da Fonseca. São Paulo: Martins Fontes, 2006. 
PERcursos Linguísticos • Vitória (ES) •v. 10 •n. 25 • 2020 • ISSN: 2236-2592 • Dossiê:

Discursos de resistência e corpos (re)existentes •

FOUCAULT, M. A ordem do discurso. São Paulo: Loyola, 1999.

FOUCAULT, M. Microfisica do poder. 6. ed. Rio de Janeiro/São Paulo: Paz e Terra, 2017.

FOUCAULT, M. O corpo utópico, as heterotopias. Posfácio de Daniel Defert. São Paulo: Edições n-1, 2013.

FOUCAULT, M. O Sujeito e o Poder. In: DREYFUS, H.; RABINOW, P. Michel Foucault, uma trajetória filosófica. Para além do estruturalismo e da hermenêutica. Tradução de Vera Portocarrero. Rio de Janeiro: Forense Universitária, 1995.

FOUCAULT, M. Vigiar e punir: nascimento da prisão. 42. ed. Petrópolis: Vozes, 2014.

GREGOLIN, M. R. Foucault e Pêcheux na análise do discurso: diálogos \& duelos. 2. ed. São Carlos: Editora Claraluz, 2006.

JENKINS, H. Cultura da convergência. São Paulo: Aleph, 2009.

LEMOS, A.; LÉVY, P. O futuro da internet: em direção a uma ciberdemocracia. 2. ed. São Paulo, SP: Paulus, 2010.

MACHADO, R. Por uma genealogia do poder. In: FOUCAULT, M. Microfísica do Poder. Rio de Janeiro/São Paulo: Paz e Terra, 2017, pp. 7-34

MILANEZ, N.; PRATA, V. (Orgs.). Filosofias do suicídio: quando o corpo tem vez. Vitória da Conquista : Labedisco, 2016.

MILANEZ, N. Corpo cheiroso, corpo gostoso : unidades corporais do sujeito no discurso. Maringá: Acta Scientiarum. Language and Culture, v. 31, n. 2, 2009, p. 215-222.

PÕE NA RODA. CURA GAY: TERAPIA OU TORTURA? A VERDADE! - Põe Na Roda. 2017. (13m09s). Disponível em: <https://youtu.be/nkEPIyvsM2A> Acesso em: 27 ago 2019. (Vídeo do Youtube)

SAMORANO, C. Discriminação e hostilidade levam mais jovens gays ao suicídio. Metrópoles, 2017. Disponível em: <https://www.metropoles.com/brasil/direitos-humanosbr/discriminacao-e-hostilidade-levam-mais-jovens-gays-ao-suicidio>. Acesso em: 25 jul. 2018 .

SILVA, A. B. B. Mentes depressivas: as três dimensões da doença do século. São Paulo: Pricipium, 2016.

WOODWARD, K. Identidade e diferença: uma introdução teórica e conceitual. In: SILVA, T. T. (org.); HALL, S.; WOODWARD, K. Identidade e diferença: a perspectiva dos estudos culturais. Petrópolis, RJ: Vozes, 2000. pp. 07-72. 